\title{
Determinants of Intention To Use Maternity Waiting Homes in Tanzania: A Study Based on Women Using MWH in Dodoma, Iringa and Morogoro
}

Habiel Benjamin Luvanda ( $\square$ luvanda09@gmail.com )

University of Dodoma

Erick Justin Mbogoro

University of Dodoma

\section{Research Article}

Keywords: Maternity waiting homes, maternal mortality, Dodoma, Iringa, Morogoro, Logistic regression

Posted Date: September 15th, 2021

DOl: https://doi.org/10.21203/rs.3.rs-871950/v1

License: (c) (1) This work is licensed under a Creative Commons Attribution 4.0 International License.

Read Full License 


\section{Abstract \\ Background}

Maternal mortality rate (MMR) in Tanzania is still persistently high. The data from Tanzania has revealed that maternal mortality ratio (MMR) has increased from 454 per 100,000 live births in 2010 to 556 per 100,000 live births by the year 2015. Establishment of Maternity Waiting Homes (MWH's) in a few regions has been one of the efforts for trying to serve lives of pregnant women from pregnancy related complication.

\section{Methods}

The study adopted a cross-sectional study design and a convenience sampling technique for recruiting the respondents.

\section{Results}

The women aged 20-34 are 10 times more likely to use the MWHs in case of future pregnancy (OR = $10.906, p=0.019)$ whereas those aged 35 to 49 are 54 times more likely to use MWHs in case of future pregnancy $(\mathrm{OR}=54.629, \mathrm{p}=0.006)$ as compared to those aged 18 to 24 years old. Women who lived 3 to 6 hours of travel to $\mathrm{MWH}$ are 11 times more likely to use $\mathrm{MWH}$ in case of future pregnancy as compared to those living at the distance of 1 to 3 hours to the MWH $(O R=11.451, p=0.032)$.

\section{Conclusion}

The results of this study have revealed some interesting findings in the issues of distance by traveling time and age of the respondent to be highly significant factors in predicting intention to use MWHs in case of future pregnancy.

\section{Background}

The global agenda on reproductive and maternal health has been well stated in the sustainable development goals (SDG3) which targets to reduce maternal deaths to 70 per 100,000 live births by 2030 [1]. Despite of the agreed targets, the recently trends shows that global maternal deaths have increased worldwide from 287,000 in 2010 to 295,000 in 2017, however, the maternal mortality rate (MMR) has significantly declined by $35 \%$ for the past 17 years from 342 per 100,000 live births to 211 per 100,000 live births [2], [3]. The statistics indicates that women are continuing dying at a steady rate of 810 per day [3]. The global adult lifetime risk of maternal death by 2017 was estimated at 1 in 190 in the world which is nearly half of the lifetime risk during the year 2000 which was 1 in 100 [3]. However, 94\% of these deaths occur in low and lower income middle-income countries whereas sub-Saharan Africa accounted 
for $66 \%$ of the global maternal deaths [3]. Based on the existing statistics on maternal mortality and the SDG3 target expected to be achieved by 2030 , significant efforts must be made to improve maternal health and reduce maternal mortality.

Maternal mortality rate (MMR) in Tanzania is still persistently high. The data from Tanzania has revealed that maternal mortality ratio (MMR) has increased from 454 per 100,000 live births in 2010 to 556 per 100,000 live births by the year 2015 [4]-[7]. Several strategies such as increasing coverage and quality primary health care services for communities in rural and remote areas, timely antenatal care visit, delivery in health facilities and timely postnatal check-up have been adopted by the government in collaboration with the UN agencies and other development partners as a necessary attempt to improve maternal health in the country [5], [8]. In spite of this increase with regard to the last two TDHS, still $37 \%$ of women in the country take risk of delivering their babies out of the health facilities. This has resulted the life time risk of maternal death to stand at 1 in 30 [5]. Some other studies show that 3/4 of maternal deaths result from the direct obstetrical complications of haemorrhage, sepsis, obstructed labour, hypertensive disorders of pregnancy and septic abortion [9], [10].

Major barriers mentioned as limiting these women from accessing better maternal health services are physical distance from the health facilities (lack of transportation), affordability of services, gender and cultural barriers (e.g., women may face unique difficulties in accessing delivery services), autonomy in making decision and economic power [11]-[13].

Many consider the experience of adaptation of maternity waiting homes (MWH's) to be a key strategy in bridging the geographical gap in obstetric care in rural areas with poor access to equipped health facilities, and urban areas where the services are available [9]. Maternity waiting homes are buildings which are located near to or within the health facilities. These MWHs offers accommodation to pregnant women with indicators of complications or who live far from health facilities access to obstetric care and opportunity to be visited regularly by a nurse, midwife or doctor [14]. Van Lonkhuijzen, et al, (2009) found that the use of MWHs has been increasing the likelihood of hospital delivery. Tanzania is among the countries which adopted MWHs as the strategy to increase timely access to maternal care for women with risky pregnancy and those living far from the health facilities [16]. MWHs are found in a few regions of Tanzania and were established few decades under the support of the United Nations Fund for Population Activities (UNFPA) as one of the pilot country [17]. Indeed, some studies have revealed that MWH's have been successful in reducing risks and complications of delivery [18], [19].

Nevertheless, the spread of these MWH's over the country has been slow as currently only a few regions are covered. Furthermore, there exists no currently known documented information on a study that has been in place to assess the intention of pregnant women towards using the MWH's services in case of future pregnancy. Therefore, this study aims to identify the factors associated with intention to use MWH's by the women in the three regions of Morogoro, Iringa and Dodoma in Tanzania.

\section{Methods And Materials}




\section{Research Design}

The study adopted a cross-sectional survey study design that was conducted from February to April 2021.

\section{Study Area}

This study was conducted in three regions of Tanzania Mainland which are Morogoro, Iringa and Dodoma. Selection of the survey areas was based on the criteria of existence of MWHs in these regions that provide services to women waiting for delivery, particularly from rural areas.

\section{Defining the population}

The population of the study involved women in reproductive age with the size for specified regions as per 2012 census estimated as: Morogoro had 539,645 persons, Iringa had 230,283 persons and Dodoma had 471,069 persons [20].

\section{The sampling procedure and sample size}

The study involved 235 respondents from the main sample (i.e. from the women attending maternity waiting houses in the selected hospitals) who were drawn using a convenience sampling technique based on their availability on the MWHs during the survey. The age range of the women was $15-47$ years.

Table 1: Sample Size for the Women Involved in the Study

\begin{tabular}{llll} 
Region & Hospital where the MWH is located & Sample Size & Percent \\
\hline Dodoma & Mvumi Mission Hospital & 119 & 50.64 \\
\hline Iringa & Ipamba Mission Hospital & 76 & 32.34 \\
\hline \multirow{2}{*}{ Morogoro } & St. Francisco Referral Hospital - Ifakara & 40 & 17.02 \\
\hline & Total & $\mathbf{2 3 5}$ & $\mathbf{1 0 0 . 0 0}$
\end{tabular}

\section{Data Collection Methods}

In this study, primary data was collected by using a standard paper questionnaire from the women attending the MWHs. The questions were asked by skilled nurses who were given a training on the 
questionnaires regarding how to properly conduct the interviews and record the responses.

\section{Variables of the Study}

The study variables are of two categories that includes outcome variable and independent variables (covariates).

Outcome variable: willingness/intention to use $\mathrm{MWH}$ in the future

Covariates: Socio-demographic, geographical and economic variables that includes region, hospital name, age, marital status, education, occupation, economic status, parity of the respondent, household size and distance to the MWHs by travel time.

\section{Data Processing, Analysis and Presentation Methods}

The data collected through standard questionnaires were transformed into computer based database using IBM-SPSS 25. Coding of the paper questionnaire was done before entry into IBM-SPSS 25 data template. The data was then cleaned up and managed by using IBM-SPSS 25 and STATA 15. Finally, descriptive and inferential statistics analyses and models were performed by using STATA 15.

\section{Ethical Approval}

Ethical approval was obtained from ethical and research clearance committee of the University of Dodoma. The permits to conduct research were obtained from the respective regional authorities and district administrations. Verbal informed consent to the respondents was obtained from each participant before beginning the interviews.

The research was conducted in accordance to all the guidelines for conducting health research involving human subjects in Tanzania as stipulated by the Tanzania Commission for Science and Technology (COSTECH), the National Institute for Medical Research (NIMR), and the Declaration of Helsinki as adopted by the Medical Association of Tanzania (MAT).

\section{Findings of the Study}

\section{Distribution of the Respondents by Demographic Characteristics of the Respondent}

The results in Table 2 below show the demographic characteristics of the respondents. Majority of the respondents that is $50.21 \%$ were from Dodoma, $29.36 \%$ were from Iringa and $17.02 \%$ were from 
Morogoro.

Majority of women were aged 18 to 24 years (38.94\%), followed by those aged 25 to 34 at $32.74 \%$ and most of the women were either married or cohabiting that is $83.12 \%$. Most of the women were selfemployed at $80.85 \%$ and mostly with primary level of education. On the other hand, $76 \%$ of the women were from the average income families, 52.04\% of the women spent about 1 to 3 hours travelling to the $\mathrm{MWH}$ and few women had parity of more than $6(16.31 \%)$.

Table 2: Distribution of the Respondents by Demographic Characteristics 
Variables

\section{Region of residence}

\begin{tabular}{lll}
\hline Iringa & 69 & 29.36 \\
\hline Dodoma & 118 & 50.21 \\
\hline Morogoro & 40 & 17.02 \\
\hline Njombe & 6 & 2.55 \\
\hline Mbeya & 1 & 0.43 \\
\hline Dar-es-Salaam & 1 & 0.43
\end{tabular}

Age of the respondent

\begin{tabular}{lll}
\hline 15 to 17 & 14 & 6.19 \\
\hline 18 to 24 & 88 & 38.94 \\
\hline 25 to 34 & 74 & 32.74 \\
\hline 35 to 49 & 50 & 22.12 \\
\hline Marital status & & \\
\hline Single & 39 & 16.88 \\
\hline Married/Cohabiting & 192 & 83.12 \\
\hline Occupation & & \\
\hline Self-employed & 190 & 80.85 \\
\hline Salary employee & 17 & 7.23 \\
\hline Unemployed & 28 & 11.91 \\
\hline Level of education & & \\
\hline No education & 50 & 21.28 \\
\hline Primary education & 101 & 42.98 \\
\hline Secondary education & 69 & 29.36 \\
\hline Post-secondary & 15 & 6.38 \\
\hline Parity of the mother & & 32.62 \\
\hline 1 Pregnancy & 76 & 30.04 \\
\hline 2 to 3 pregnancies & 70 & 21.03 \\
\hline 4 to 5 pregnancies & 49 & \\
\hline
\end{tabular}


Household size

\begin{tabular}{|c|c|c|}
\hline 1 to 3 & 98 & 43.36 \\
\hline 4 to 6 & 86 & 38.05 \\
\hline 7 or more & 42 & 18.58 \\
\hline
\end{tabular}

Household economic status

\begin{tabular}{|ccc|} 
Poor family & 29 & 12.89 \\
\hline Average income & 171 & 76.00 \\
\hline Well-off family & 25 & 11.11 \\
\hline
\end{tabular}

Distance to MWH by travel time

\begin{tabular}{lll}
\hline Less than 1 hour & 32 & 14.48 \\
\hline 1 to 3 hours & 115 & 52.04 \\
\hline 3 to 6 hours & 69 & 31.22 \\
\hline More than 6 hours & 5 & 2.26
\end{tabular}

\section{Factors Associated with Pregnant Women Intention to Use MWH's in Case of Future Pregnancy}

In this case, we run the unadjusted and adjusted multivariate logistic regression model for binary outcomes to determine the factors associated with women intention to use MWHs in case of future pregnancy.

\section{Unadjusted Logistic Regression Model}

Upon running the unadjusted multivariate logistic regression model, the covariates of age, parity, household size, economic status of the family and distance of MWH by travel time were significant at $5 \%$ level as clearly shown in Table 3 below. These significant covariates were included in the final adjusted model (Table 4) that was interpreted for the factors associated with women willingness to use MWH in case of future pregnancy. The reference category selected for both covariates was that with the highest frequency because some of the first/last categories had very few observations that could affect the results. 
Outcome: Will Use MWH Coef. p-value [95\% Conf Interval] Sig Region of residence

\begin{tabular}{lllll}
\hline Iringa & .499 & .401 & .098 & 2.528 \\
\hline Dodoma (REF) & 1 &. &. &. \\
\hline Morogoro & .581 & .612 & .072 & 4.722 \\
\hline Njombe & 1 &. &. &. \\
\hline Dar-es-Salaam & 1 &. &. &. \\
\hline
\end{tabular}

\section{Current age}

\begin{tabular}{|c|c|c|c|c|c|}
\hline 15 to 17 & .418 & .554 & .023 & 7.518 & \\
\hline 18 to 24 (REF) & 1 & . & . & . & \\
\hline 25 to 34 & 39.085 & .019 & 1.829 & 835.105 & $\star *$ \\
\hline 35 to 49 & 1287.945 & .008 & 6.295 & 263491.22 & $\star * \star$ \\
\hline \multicolumn{6}{|l|}{ Marital status } \\
\hline Single & .742 & .749 & .119 & 4.615 & \\
\hline Married/cohabit (REF) & 1 & . & . & . & \\
\hline \multicolumn{6}{|l|}{ Occupation } \\
\hline Self-employed (REF) & 1 & . & . & . & \\
\hline Salary employee & 1 & . & . & . & \\
\hline Unemployed & 1.743 & .583 & .24 & 12.635 & \\
\hline \multicolumn{6}{|l|}{ Level of education } \\
\hline No education & 1.051 & .958 & .163 & 6.786 & \\
\hline Primary (REF) & 1 & . & . & . & \\
\hline Secondary education & 2.652 & .27 & .469 & 14.999 & \\
\hline Post-secondary & 1 & . & . & . & \\
\hline \multicolumn{6}{|l|}{ Parity of the mother } \\
\hline 1 (REF) & 1 & . & . & . & \\
\hline 2 to 3 & .419 & .354 & .066 & 2.639 & \\
\hline 4 to 5 & .063 & .117 & .002 & 1.997 & \\
\hline 6 or more & 0 & .007 & 0 & .11 & $* * *$ \\
\hline
\end{tabular}


Age when got first

\begin{tabular}{|c|c|c|c|c|c|}
\hline 13 to 17 & .659 & .663 & .101 & 4.295 & \\
\hline$\sim b(\mathrm{REF})$ & 1 & . & . & . & \\
\hline 25 to 34 & .177 & .39 & .003 & 9.183 & \\
\hline 35 to 49 & 1 & . & . & & \\
\hline \multicolumn{6}{|l|}{ Household size } \\
\hline 1 to3 (REF) & 1 & . & . & . & \\
\hline 4 to 6 & 7.807 & .04 & 1.101 & 55.368 & ** \\
\hline 7 or more & 4.278 & .187 & .493 & 37.113 & \\
\hline \multicolumn{6}{|c|}{ Household economic } \\
\hline Poor family & .039 & .001 & .005 & .283 & $\star \star \star *$ \\
\hline Average (REF) & 1 & . & . & . & \\
\hline Well-off family & .205 & .164 & .022 & 1.903 & \\
\hline \multicolumn{6}{|c|}{ Distance by travel time } \\
\hline Less than 1 hour & .215 & .131 & .029 & 1.583 & \\
\hline 1 to 3 hours (REF) & 1 & . & . & . & \\
\hline 3 to 6 hours & 19.166 & .033 & 1.262 & 291.098 & ** \\
\hline More than 6 hours & 1 & . & . & & \\
\hline Constant & 10.665 & .003 & 2.21 & 51.482 & $\star \star \star$ \\
\hline
\end{tabular}

$\star \star \star ~ p<.01, * \star p<.05, * p<.1 ; \mathrm{HH}=$ Household

\section{Adjusted Multivariate Logistic Regression Model}

Table 4 below shows the results of the adjusted multivariate logistic regression model. Generally, both covariates included in the final model have significant categories except for the household size which has no significant categories.

For respondent age, the age categories of 25-34 and 35-49 were significant at 5\% level. The women aged 20-34 are 10 times more likely to use the MWHs in case of future pregnancy $(O R=10.906, p=0.019)$ whereas those aged 35 to 49 are 54 times more likely to use MWHs in case of future pregnancy $(\mathrm{OR}=54.629, \mathrm{p}=0.006)$ as compared to those aged 18 to 24 years old. 
Women with parity of 6 or more are the only significant category and are less likely to use MWHs in case of future pregnancy $(\mathrm{OR}=0.012, \mathrm{p}=0.006)$ as compared to women with parity of 1 pregnancy. On the other hand, poor household status is significant as the women from these families are less likely to use MWHs in case of future pregnancy $(\mathrm{OR}=0.127, \mathrm{p}=0.002)$ as compared to average income families.

Women who lived 3 to 6 hours of travel to $\mathrm{MWH}$ are 11 times more likely to use $\mathrm{MWH}$ in case of future pregnancy as compared to those living at the distance of 1 to 3 hours to the MWH $(O R=11.451, p=0.032)$.

\section{Table 4: Adjusted Logistic regression}


Outcome: Will Use MWH Coef. p-value [95\% Conf Interval] Sig Current age

\begin{tabular}{llllll}
\hline 15 to 17 & .489 & .482 & .066 & 3.6 & \\
\hline 18 to 24 (REF) & 1 &. &. &. & \\
\hline 25 to 34 & 16.206 & .027 & 1.375 & 191.004 & $* *$ \\
\hline 35 to 49 & 809.241 & .001 & 13.161 & 49758.854 & $* * *$ \\
\hline
\end{tabular}

\section{Parity of the mother}

\begin{tabular}{llllll}
1 (REF) & 1 &. &. &. \\
\hline 2 to 3 & .424 & .269 & .093 & 1.943 & \\
\hline 4 to 5 & .105 & .121 & .006 & 1.808 & \\
\hline 6 or more & .001 & .001 & 0 & .043 & ***
\end{tabular}

\section{Distance by Travel Time}

\begin{tabular}{|c|c|c|c|c|c|}
\hline Less than 1 hour & .663 & .59 & .148 & 2.956 & \\
\hline 1 to 3 hours (REF) & 1 & . & . & & \\
\hline 3 to 6 hours & 11.451 & .032 & 1.23 & 106.629 & $\star \star$ \\
\hline More than 6 hours & 1 & . & & ${ }^{\circ}$ & \\
\hline \multicolumn{6}{|l|}{ HH size } \\
\hline 1 to3 (REF) & 1 & & . & . & \\
\hline 4 to 6 & 4.12 & .103 & .752 & 22.578 & \\
\hline 7 or more & 3.302 & .23 & .469 & 23.263 & \\
\hline \multicolumn{6}{|l|}{ HH economic } \\
\hline Poor family & .078 & .001 & .017 & .362 & 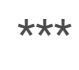 \\
\hline Average (REF) & 1 & . & & . & \\
\hline Well-off family & .27 & .174 & .041 & 1.785 & \\
\hline Constant & 9.385 & 0 & 2.736 & 32.192 & $\star \star *$ \\
\hline
\end{tabular}

${ }^{* * *} p<.01,{ }^{* *} p<.05,{ }^{*} p<.1 ; H H=$ Household

\section{Discussion}


Women intention to use MWH in case of near pregnancy is an important thing to study as to assess whether the MWHs are still in need in the future. Similar studies have been done in Ethiopia to determine the factors associated with maternity waiting home use among women [18] and predictors of intention to use maternity waiting home [19], [21]. This study came with results that showed that, women aged 25 to 34 are 16 times more likely to use $\mathrm{MWH}$ in case of future pregnancy (OR: $16.206,95 \% \mathrm{Cl} 1.375$ to 191.004), whereas those aged 35 to 49 have very high odds of using MWH in case of future pregnancy, that is 809 times more likely to use MWH (OR: $809.241,95 \% \mathrm{Cl} 13.161$ to $49,758.854$ ) as compared to those aged 18 to 24 years.

The results show that parity and economic status of the family are not highly predicting future use of MWHs. Socio-economic status results which indicates that poorer families are less likely to use $\mathrm{MWH}$ (OR: $0.078,95 \%$ Cl 0.017 to 0.362 ) differs from to those of the study by Fogliati et al., (2017) that revealed that poorer women were more likely to access $\mathrm{MWH}$ than richer families (OR: 1.38).

The results also differs from other studies conducted in Ethiopia as the studies showed that occupation and marital status were significant predictors of use of maternity waiting homes [17], [18]. A study on predictors of intention to use MWH used rather a theory of planned behaviour covariates that are perceptions [19] which are different from the factors used in this study.

However, the results regarding the travel time to the $\mathrm{MWH}$ are similar to other studies as this study shows women living a long distance to $\mathrm{MWH}$ are more likely to use MWH than those living nearby (OR: 11.451, $95 \% \mathrm{Cl} 1.23$ to 106.629 ) as similar results are obtained for women living in Jimma Zone, Ethiopia whereas women staying more than 30 minutes away from $\mathrm{MWH}$ had higher odds of using $\mathrm{MWH}$ than those within 30 minutes of travel (OR: $2.37,95 \% \mathrm{Cl} 1.80$ to 3.13 ) [18].

\section{Conclusion}

Since facility based studies like this one lack the results of mothers who never stayed at MWHs, we recommend household survey to be conducted in order to make a more informative comparison between $\mathrm{MWH}$ users and nonusers. Furthermore, qualitative studies can be conducted to include key informants on whether these MWHs can provide a long term solution to maternal and child morbidity and mortality in the county as it is still a puzzle yet to be solved.

Likewise, there is a need to build more MWHs nearby to the hospitals that usually receives many referral cases of pregnant women from smaller health centers as women with risky pregnancy needs a closer monitoring by health workers during the time they await delivery.

\section{Abbreviations}

ANC

Antenatal Care; MMR-Maternal Mortality Ratio; MWH-Maternity Waiting Home 


\section{Declarations}

\section{Acknowledgement}

We would like to convey our appreciations to the University of Dodoma and all the local authorities for granting us permission to conduct our study, research assistants for their data collection task and the pregnant women who gave their time to respond to the questionnaires.

\section{Funding}

This study was funded by the University of Dodoma through the Junior Academic Staff Research Grants (JAS).

\section{Disclosure}

The authors declare no conflict of interest for this work.

\section{Consent for publication}

Not applicable.

\section{Data Availability}

The data used in this study are available upon request to the authors and approval by the project funders.

\section{Author Contribution}

Conception of the Study: HBL, and EJM. Data analysis and interpretation: HBL. Drafting the Manuscript: HBL, EJM. Critical revision of the Manuscript: HBL and EJM. Writing of the final Manuscript: HBL and EJM. Final approval of the version to be published: HBL and EJM.

\section{References}

1. WHO, World health statistics 2020: monitoring health for the SDGs, sustainable development goals. Geneva, 2020.

2. WHO and Worldbank, "Maternal Mortality: 1990 to 2010," 2010.

3. WHO, UNICEF, UNFPA, World Bank, and United nations population division, "Trends in maternal mortality: 2000 to 2017: estimates by WHO, UNICEF, UNFPA, World Bank Group and the United Nations Population Division. Geneva: World Health Organization; 2019.," 2019. 
4. A. Lilungulu, D. Bintabara, S. Mujungu, E. Chiwanga, P. Chetto, and M. Nassoro, "Incidence and Predictors of Maternal and Perinatal Mortality among Women with Severe Maternal Outcomes: A Tanzanian Facility-Based Survey for Improving Maternal and Newborn Care," Obstet. Gynecol. Int., vol. 2020, 2020.

5. MoHCDGEC, "Tanzania Demographic and Health Survey and Malaria Indicator Survey (TDHS-MIS) 2015-16," 2016.

6. National Bureau of Statistics \& ICF Macro, "Tanzania Demographic and Health Survey," Tanzania Demogr. Heal. Surv., no. April, pp. 138-141, 2011.

7. V. M. Bwana, S. F. R. Id, I. R. Mremi, E. P. Lyimo, and L. E. G. Mboera, "Patterns and causes of hospital maternal mortality in," PLoS One, vol. 24, no. 2006, pp. 1-22, 2019.

8. G. Todd and M. Mamdani, "Tanzania and the Sustainable Development Goals," 2017.

9. WHO, "Maternity Waiting Homes: A review of experiences," 1996.

10. S. Neal et al., "The causes of maternal mortality in adolescents in low and middle income countries: Systematic review of the literature," BMC Pregnancy Childbirth, vol. 16, no. 1, 2016.

11. R. Dahab and D. Sakellariou, "Barriers to accessing maternal care in low income countries in Africa: A systematic review," Int. J. Environ. Res. Public Health, vol. 17, no. 12, pp. 1-17, 2020.

12. T. W. John, D. A. Mkoka, G. Frumence, and I. Goicolea, "An account for barriers and strategies in fulfilling women's right to quality maternal health care: A qualitative study from rural Tanzania," $B M C$ Pregnancy Childbirth, vol. 18, no. 1, pp. 1-10, 2018.

13. A. Z. Kea, O. Tulloch, D. G. Datiko, S. Theobald, and M. C. Kok, "Exploring barriers to the use of formal maternal health services and priority areas for action in Sidama zone, southern Ethiopia," BMC Pregnancy Childbirth, vol. 18, no. 1, pp. 1-12, 2018.

14. J. R. Lori, A. C. Wadsworth, M. L. Munro, and S. Rominski, "Promoting access: The use of maternity waiting homes to achieve safe motherhood," Midwifery, vol. 29, no. 10, pp. 1095-1102, 2013.

15. L. Van Lonkhuijzen, J. Stekelenburg, and J. Van Roosmalen, "Maternity waiting facilities for improving maternal and neonatal outcome in low-resource countries," Cochrane Database Syst. Rev., no. 3, 2009.

16. K. Singh, I. S. Speizer, E. T. Kim, C. Lemani, J. H. Tang, and A. Phoya, "Evaluation of a maternity waiting home and community education program in two districts of Malawi," BMC Pregnancy Childbirth, vol. 18, no. 1, pp. 1-14, 2018.

17. P. Fogliati, M. Straneo, S. Mangi, G. Azzimonti, F. Kisika, and G. Putoto, "A new use for an old tool: Maternity waiting homes to improve equity in rural childbirth care. Results from a cross-sectional hospital and community survey in Tanzania," Health Policy Plan., vol. 32, no. 10, pp. 1354-1360, 2017.

18. J. Kurji et al., "Factors associated with maternity waiting home use among women in Jimma Zone, Ethiopia: A multilevel cross-sectional analysis," BMJ Open, vol. 9, no. 8, pp. 1-9, 2019. 
19. T. Nigussie, R. Yaekob, M. Geremew, and A. Asefa, "Predictors of intention to use maternity waiting home among pregnant women in bench maji zone, southwest ethiopia using the theory of planned behavior," Int. J. Womens. Health, vol. 12, pp. 901-910, 2020.

20. National Bureau of Statistics, "2012 Population and housing census; Population Distribution by Adminstrative Areas," Natl. Bur. Stat., 2013.

21. W. Gezimu, Y. B. Bitewa, M. T. Tesema, and T. E. Wonde, "Intention to use maternity waiting home and associated factors among pregnant women in Gamo Gofa zone, Southern Ethiopia, 2019," PLoS One, vol. 16, no. 5 May, pp. 1-16, 2021. 